\title{
Costs of production loss and primary health care interventions for return-to-work of sick- listed workers in Sweden
}

Jan Persson, Lars Bernfort, Charlotte Wåhlin, Birgitta Öberg and Kerstin Ekberg

\author{
Linköping University Post Print
}

Tweet

N.B.: When citing this work, cite the original article.

Original Publication:

Jan Persson, Lars Bernfort, Charlotte Wåhlin, Birgitta Öberg and Kerstin Ekberg, Costs of production loss and primary health care interventions for return-to-work of sick-listed workers in Sweden, 2015, Disability and rehabilitation, (37), 9, 771-776.

http://dx.doi.org/10.3109/09638288.2014.941021

Copyright: Informa Healthcare http://informahealthcare.com/

Postprint available at: Linköping University Electronic Press

http://urn.kb.se/resolve?urn=urn:nbn:se:liu:diva-114181 


\section{Costs of production loss and primary healthcare interventions for return-to-work of sick-listed workers in Sweden}

Jan Persson, PhD, ${ }^{1}$ Lars Bernfort, PhD, ${ }^{1}$ Charlotte Wåhlin, PhD, ${ }^{2,3}$, Birgitta Öberg, PhD ${ }^{4}$, Kerstin Ekberg, PhD ${ }^{5}$

1 Division of Health Care Analysis, Department of Medical and Health Sciences, Linköping University, Linköping, Sweden

2 Intervention and Implementation Research Unit, Institute of Environmental Medicine, Karolinska Institutet, Stockholm, Sweden, and

3 Occupational and Environmental Medicine Center, and Department of Clinical and Experimental Medicine, Linköping University, Linköping, Sweden

4 Division of Physiotherapy, Department of Medical and Health Sciences, Linköping University, Linköping, Sweden

5 National Centre for Work and Rehabilitation, Department of Medical and Health Sciences, Linköping University, Linköping, Sweden

Key words

Sick leave, rehabilitation, societal costs, economic analysis, musculoskeletal disorders, mental disorders, Sweden. 


\section{Abstract \\ Purpose}

The aim of this study was to investigate, from the perspective of society, the costs of sick leave and rehabilitation of recently sick-listed workers with musculoskeletal disorders (MSD) or mental disorders (MD).

Methods

In a prospective cohort study, 812 sick-listed workers with MSD (518) or MD (294) were included. Data on consumption of healthcare and production loss were collected over six months from an administrative casebook system of the healthcare provider. Production loss was estimated based on the number of sick-leave days. Societal costs were based on the human capital approach.

Results

The mean costs of production loss per person were EUR 5978 (MSD) and EUR 6381 (MD). Healthcare interventions accounted for $9.3 \%$ (MSD) and $8.2 \%$ (MD) of the costs of production loss. Corresponding figures for rehabilitation activities were $3.7 \%$ (MSD) and $3.1 \%$ (MD). Healthcare interventions were received by about $95 \%$ in both diagnostic groups. For nearly half of the cohort, no rehabilitation intervention at all was provided.

Conclusions

Costs associated with sick leave were dominated by production loss. Resources invested in rehabilitation were small. By increasing investment in early rehabilitation, costs to society and the individual may be reduced. 


\section{Introduction}

Previous research on costs for return-to-work interventions (RTW) for people who are sick-listed due to musculoskeletal disorders (MSD) and mental disorders (MD) has primarily focused on studying the effectiveness and cost-effectiveness of different RTW interventions. Published evidence is not conclusive and the effectiveness of RTW programmes depends on design and target groups. For example, a multi-stage RTW programme was shown to be efficient, and likely to be cost-effective, compared with the usual care for individuals with low-back pain (LBP), while a similar RTW programme was found to be expensive and lacked effect compared with the usual care for people suffering from distress $[1,2]$. For those with LBP, a multidisciplinary intervention was expensive but had no effect at group level. However, in a sub-group of employees who felt that they risked losing their job or had very little influence over their work situation, the intervention was efficient and probably cost-effective [3]. A participatory RTW intervention for individuals with MSD has been shown to be cost-effective [4].

Some reviews on workplace-based RTW interventions have been published. A conclusion drawn is that workplace-based interventions might reduce the duration of work inability, and thereby associated sick leave and costs [5]. For individuals on long-term sick leave due to back pain, interventions including interaction between employees, care personnel and employers appear to be more efficient and cost-effective than other workplace-linked interventions [6]. A review of worksite mental health interventions concluded that preventive interventions might be cost-effective, but RTW interventions did not seem to be cost-effective [7]. A review of interventions in community and workplace settings concluded that intensive interventions were less efficient than simple ones, and therefore more expensive interventions should be undertaken with caution [8].

There are a few cost-of-illness studies published for musculoskeletal disorders [9-11], but we have found no previously published study analysing a cohort of sick-listed individuals in order to 
determine what actually happens to them and what rehabilitation resources the healthcare system invests in the return-to-work process.

Sickness absences impose a substantial economic burden on affected individuals, employers, and society as a whole. In Sweden, the diagnoses associated with most sickness absence are those related to MSD (31\% of the total sick leave) and MD (37\% of the total sick leave). (Figures for 2009. Social Insurance Report 2011:4. The Swedish Social Insurance Agency.)

The probability of returning to work decreases with the length of the sick leave [12]. Early rehabilitation interventions and measures directed to avoiding long-term sick leave are therefore of great importance.

In Sweden the employer pays $80 \%$ of the salary during the first two weeks of sick leave. After two weeks sickness benefit is paid by the Social Insurance Agency. Costs for individuals due to sick leave mainly consist of income loss, i.e. the difference between their ordinary salary and the sickness benefit they receive. In Sweden the level of sickness benefit is $80 \%$ of the ordinary salary, up to a ceiling value of EUR 30162 (SEK 330 000) per year, for the first year. Thereafter the sickness benefit is 75\% of maximally EUR 30162 until day 550. The cost to society due to individuals falling ill and thereby being sick-listed is the sum of all the costs that occur as a consequence of the sickness. Societal costs include production loss, work rehabilitation costs, and healthcare costs.

In this explorative study we describe the costs incurred in a cohort of workers who have been sicklisted due to MSD or MD. The costs described relate to a time period of six months, starting with the second day of sick leave as the first day is a qualifying day of sickness.

The aim of this study was to investigate costs of sick leave and rehabilitation of recently sick-listed workers, from the perspective of society. Since the study has a healthcare perspective, employers interventions were not included.

The study was approved by the Regional Ethics Committee in Linköping. 


\section{Study population and methods}

\section{Research design and study population}

The study design was a prospective cohort study carried out in the county of Östergötland, which is socioeconomically representative of Sweden. The study, which has been described elsewhere [13], comprises workers who were granted sick leave due to MSD or MD at 39 primary care centres and four occupational healthcare centres.

The subjects were recruited from June 2008 to December 2009. Inclusion criteria were: age between 18 and 65 years, ability to communicate in Swedish and being on sick leave due to MSD or $M D$, including depression. All cohort members responded to a baseline questionnaire within three weeks of their first day of certified medical sickness, which in practice means that they had been on sick leave for about four weeks, as the first week on sick leave does not require a doctor's certificate in Sweden. The baseline questionnaire comprised questions on demographic data, employment situation, and socioeconomic status. Questions on lifestyle, health, work ability, coping, work conditions, and prospects for future work were also included.

A total of 1375 sick-listed individuals fulfilled the criteria and agreed to participate [13]. The baseline questionnaire was sent by post to all participants, and 935 of them responded to the questionnaire and fulfilled the inclusion criteria (70\%). The average age was 46 years (SD 11 years); 30\% were men and $70 \%$ were women; $20 \%$ had left school after nine years of compulsory education, and $26 \%$ had a university education. Those included in the cohort were compared with the 413 non-responders for the parameters that were accessible. There was no significant difference in the distribution of diagnoses between the cohort members and the non-responders, but there was a tendency to a better response rate among those with $\operatorname{MSD}(p=.071)$. The two groups differed in age $(p<.001)$; nonresponders were younger (mean 42 years, SD 11 years) than respondents (mean 46 years, SD 11 years), with a higher proportion of non-responders among those younger than 39 years of age; the 
proportion above 50 years of age was higher among respondents. The proportion of men was higher among non-responders $(35 \%)$ than among respondents $(29 \%)(p<.014)$. There was no difference between respondents and non-responders in rate of return-to-work during the one-year follow-up period $(p=.807)$.

The present study comprised employed people who were registered in the electronic casebook system of the county council with data on costs available. This study cohort resulted in 812 cases, i.e., $87 \%$ of the baseline respondents. In total, 518 (64 \%) had MSD and 320 (36\%) had MD as the main diagnosis. The distribution of MSD and MD groups in our study cohort was the same as in the baseline group of respondents. The study cohort was therefore considered representative.

The profession was coded according to the Swedish standard for occupational classification (Statistics Sweden) with 9 occupational groups categorized into white collar (managers, academics, etc.), pink collar (care, service, salespersons, etc.) and blue collar (industry, etc.).

Production loss was estimated, based on a slightly reduced sample size due to missing information on gross salary in some cases ( $14 \%$ for the MSD group, $9 \%$ for the MD group).The economic analysis reported here comprises a timeframe of six months.

\section{Methods}

\section{Questionnaire}

All respondents filled in a baseline questionnaire comprising information on demographics, including income, health and work ability, personal resources and work conditions. In this study occupational group, age, educational level, health-related quality of life (EQ-5D) [14] and work ability (Work ability Index, [15]) were used. 


\section{Costing}

Data on costs are based on information about rehabilitation measures performed, taken from the electronic casebook system at the county council; production costs are based on self-reported income in the questionnaire. Resources are priced according to a societal perspective, implying that opportunity costs are applied [16].

Rehabilitative measures in the public healthcare system

The quantity of healthcare resources consumed was collected from the county council's electronic casebook system, where patients' healthcare history is gathered and diagnoses, treatments, admissions, investigations, laboratory tests and results, drugs etc. are included. Each casebook was read through and all consumption of healthcare related to the relevant main diagnoses MSD and MD was included in the analysis. As an approximation of opportunity costs, the price of healthcare resources consumed is based on standard prices (i.e. official price lists) for measures, tests, time for different personnel categories, etc.

The individuals were offered healthcare interventions according to common practice. A number of professionals were involved, i.e. physicians, nurses, physiotherapists, psychologists, occupational therapists and behavioural therapists. Also, multiprofessional meetings were arranged. Other caregivers were consulted in a few cases. Rehabilitative activities were healthcare advice, behavioural treatment (therapeutic conversation, cognitive therapy, body awareness), exercise therapy/physical activity, manual treatment (manual, acupuncture/TENS), ergonomic/ADL, equipment/orthosis and other [17]. The interventions included healthcare consultations with personal meetings as well as indirect contacts, i.e. by phone or by letter, and rehabilitation activities. Costs in EUR were derived from SEK using a conversion factor of 0.0914 (January 1, 2009). 
Production loss is incurred as individuals are unable to perform their regular work due to sickness. According to welfare economic theory, production loss is estimated as gross salary (including taxes) for the individual on sick leave. This approach to valuation of people's time, the so-called human capital approach [18], implies that time lost to ordinary production or other tasks due to sickness is always a lost resource and therefore a cost to society. Estimations of production loss are based on self-reported income.

Sick leave

The sick-leave periods, expressed in full-day equivalents, for individuals included in the study were collected from the registries held by the Swedish Social Insurance Agency.

\section{Statistical analyses}

The distributions of costs are described by means, medians and standard deviations (SD) in order to demonstrate dispersion and skewness. For healthcare interventions, total costs and average costs for those who received any intervention are shown. Societal costs are demonstrated by averages for the total cohorts.

Differences between the MSD and MD groups with regard to utilisation of healthcare and costs were tested by means of Pearson chi-square tests. Mean costs in the two groups of healthcare consultations, indirect contacts and medical rehabilitation were compared by using the MannWhitney two-tailed U-test.

Differences between MSD and MD groups with regard to costs of production loss were tested by means of 2-tailed t-tests. 


\section{Results}

The total cohort was investigated with regard to demographics, income, quality of life index (EQ-5D) and work ability index (WAI score). White-collar professions were more common in the MD group (42\%) than in the MSD group (16\%), pink-collar professions were equally distributed (42\% MSD, 43\% $M D$ ), and blue-collar professions more common in the MSD group ( $42 \%$ versus $15 \%$ in the MD group). The mean age was 47 years (MSD) and 44 years (MD). Leaving school after nine years of compulsory education was more common in the MSD group (26\%) than in the MD group 10\%); and a university degree was more common in the MD group (26\%) than in the MSD group (17\%). Gross income was in total EUR 1940/month (MSD 1881, MD 2040), the EQ-5D index was on average 0.47 (MSD 0.44, MD 0.51), and the WAI index was on average 3.6 (MSD 3.6, MD 3.5). These data, which are in concordance with corresponding characteristics of the original cohort, show that the MD group is somewhat younger and better educated than the MSD group; the MD group also has a somewhat higher health-related quality of life, while their work ability is lower.

In the following we report two aspects of utilisation and costs of services. Firstly, the analysis provides a description of the utilization of services provided by the various professional groups of the healthcare services, and the costing distributions of those patients who received at least one of these services. This includes total costs, means and medians of costs of all health care interventions, as seen in table 1). The corresponding report of the subgroup of these activities which were categorised as rehabilitative is shown in table 2 . Secondly, in table 3 the societal costs are reported. These include the use of resources for healthcare interventions as well as production losses due to sickness absence. Here, the total cohort provides the basis for the cost analyses.

\section{Healthcare interventions}


Healthcare interventions, shown in table 1, include personal visits as well as indirect consultations by phone or by letter, and rehabilitative activities.

\begin{tabular}{|c|c|c|c|c|c|c|c|c|c|}
\hline \multirow[b]{2}{*}{ Professional category } & \multicolumn{3}{|c|}{ Utilisation } & \multicolumn{3}{|c|}{$\begin{array}{c}\text { Costs (MSD) } \\
\text { (euro) }\end{array}$} & \multicolumn{3}{|c|}{$\begin{array}{c}\text { Costs (MD) } \\
\text { (euro) }\end{array}$} \\
\hline & $\begin{array}{l}\mathrm{MSD} \\
\mathrm{N}(\%)\end{array}$ & $\begin{array}{l}\mathrm{MD} \\
\mathrm{N}(\%)\end{array}$ & p-value & Total costs & Mean costs & $\begin{array}{l}\text { Median } \\
\text { costs }\end{array}$ & Total costs & Mean costs & $\begin{array}{c}\text { Median } \\
\text { costs }\end{array}$ \\
\hline Physician & $477(82.1 \%)$ & $278(94.6 \%)$ & 0.185 & 163475 & 343 SD 313 & 237 & 90106 & 324 SD 308 & 237 \\
\hline Nurse & $59(11.4 \%)$ & $45(15.3 \%)$ & 0.109 & 7721 & 131 SD 230 & 43 & 7343 & 163 SD 211 & 47 \\
\hline Physiotherapist & $236(45.6 \%)$ & $43(14.6 \%)$ & 0.000 & 83881 & $388 \mathrm{SD} 437$ & 183 & 18511 & 454 SD 543 & 257 \\
\hline $\begin{array}{l}\text { Occupational } \\
\text { therapist }\end{array}$ & $53(10.2 \%)$ & $24(8.2 \%)$ & 0.334 & 8784 & $168 \mathrm{SD} 161$ & 76 & 3408 & 142 SD 117 & 76 \\
\hline Behavioural therapist & $18(3.5 \%)$ & $83(31.6 \%)$ & 0.000 & 5360 & 298 SD 314 & 175 & 25691 & 275 SD 224 & 175 \\
\hline $\begin{array}{l}\text { Psychologist and } \\
\text { psychotherapist, } \\
\text { multi-professional } \\
\text { meeting, and other } \\
\text { caregivers }\end{array}$ & $159(30.7 \%)$ & $108(36.7 \%)$ & 0.078 & 8981 & 56 SD 107 & 30 & 8717 & 81 SD 128 & 30 \\
\hline Total & $488(24.2 \%)$ & $282(95.9 \%)$ & 0.290 & 288202 & 591 SD 638 & 325 & 154674 & 548 SD 602 & 353 \\
\hline
\end{tabular}

Table 1. Healthcare interventions - utilisation and costs (euro). Study cohorts: musculoskeletal disorders (MSD, sample size 518) and mental disorders (MD, sample size 294). Means, standard deviations (SD) and medians over those who received one or several interventions.

The most extensively utilised groups of professionals are physicians, nurses, physiotherapists and behavioural therapists. As seen in table 1 , the rate of healthcare interventions by a physiotherapist is significantly higher for the MSD group than for the MD group (45.6\% vs. $14.6 \%$ ), while the rate of healthcare consultation by a behavioural therapist is significantly higher for those in the MD group (31.6\% vs. 3.5\%). Except for these differences, there are only minor differences. In order for sickness certification to be issued, all patients must have at least one consultation with a physician. In a few cases this was accomplished by a physician within hospital or occupational health care, resulting in slightly less than $100 \%$ utilization of physicians in primary healthcare. 
In the MSD group, $94.2 \%$ received healthcare intervention from any of the professionals, amounting to a mean cost of EUR 591, averaged over those who had at least one healthcare visit. In the MD group, $95.9 \%$ received at least one healthcare intervention to any of the professionals, amounting to a total mean cost of EUR 548, averaged over those who had at least one healthcare visit

Costs of interventions in primary healthcare are, in general, concentrated to the lower costing areas with few expensive interventions, as can be seen from the low median costs compared with the mean costs. High costs are mainly due to repeated consultations or personal visits in some cases.

\section{Rehabilitation activities}

Rehabilitative activities are mainly carried out by physiotherapists addressing the MSD patients (45.2 \% versus $14.3 \%$ in the MD group) and behavioural therapists addressing the MD patients ( $30.6 \%$ versus $3.1 \%$ in the MSD group), as shown in table 2 . Other professions involved are nurses (5.4\% of MSD and $8.8 \%$ of MD patients) and occupational therapists (9.1 \% of MSD and $6.8 \%$ of MD patients). In the MSD group, $52.5 \%$ received some kind of rehabilitative intervention, amounting to a total mean cost of EUR 419, averaged over those who received at least one intervention. In the MD group, $54.4 \%$ received some kind of rehabilitative intervention, amounting to a total mean cost of EUR 379 , averaged over those who received an intervention. 
Table 2. Rehabilitation activities- utilisation and costs (euro). Study cohorts: musculoskeletal disorders (MSD, sample size 518) and mental disorders (MD, sample size 294). Means, standard deviations (SD) and medians over those who received one or several interventions.

\begin{tabular}{|c|c|c|c|c|c|c|c|c|c|}
\hline \multirow[b]{2}{*}{ Professional category } & \multicolumn{3}{|c|}{ Utilisation } & \multicolumn{3}{|c|}{$\begin{array}{l}\text { Costs (MSD) } \\
\text { (euro) }\end{array}$} & \multicolumn{3}{|c|}{$\begin{array}{c}\text { Costs (MD) } \\
\text { (euro) }\end{array}$} \\
\hline & $\begin{array}{l}\text { MSD } \\
\mathrm{N}(\%)\end{array}$ & $\begin{array}{l}\mathrm{MD} \\
\mathrm{N}(\%)\end{array}$ & p-value & Total costs & Mean costs & Median costs & Total costs & Mean costs & Median costs \\
\hline Physician & $2.9 \%$ & $3.9 \%$ & 0.894 & 1817 & $121 \mathrm{SD} 60$ & 119 & 748 & $83 \mathrm{SD} 53$ & 118 \\
\hline Nurse & $\begin{array}{c}28 \\
5.4 \%\end{array}$ & $\begin{array}{c}26 \\
8.8 \%\end{array}$ & 0.059 & 5664 & 202 SD 312 & 71 & 5625 & 216 SD 241 & 91 \\
\hline Physiotherapist & $\begin{array}{r}234 \\
45.2 \%\end{array}$ & $14.3 \%$ & 0.000 & 92303 & 394 SD 433 & 193 & 18523 & 441 SD 501 & 257 \\
\hline $\begin{array}{l}\text { Oocupational } \\
\text { therapist }\end{array}$ & $9.1 \%$ & $\begin{array}{l}20 \\
6.8 \%\end{array}$ & 0.258 & 6011 & $128 \mathrm{SD} 86$ & 76 & 2769 & $138 \mathrm{SD} 112$ & 76 \\
\hline Behavioural therapist & $\begin{array}{l}16 \\
3.1 \%\end{array}$ & $\begin{array}{c}90 \\
30.6 \%\end{array}$ & 0.000 & 5184 & 324 SD 325 & 175 & 25392 & 282 SD 221 & 175 \\
\hline $\begin{array}{l}\text { Psychologist and } \\
\text { psychotherapist, } \\
\text { multi-professional } \\
\text { meeting, and other } \\
\text { caregivers }\end{array}$ & $3.3 \%$ & $\begin{array}{c}25 \\
8.5 \%\end{array}$ & 0.001 & 2961 & 148 SD 136 & 72 & 5292 & 160 SD 175 & 87 \\
\hline Total & $\begin{array}{l}272 \\
52.5 \%\end{array}$ & $\begin{array}{l}154 \\
54.4 \%\end{array}$ & 0.972 & 113941 & $419 \mathrm{SD} 483$ & 206 & 58350 & 379 SD 441 & 217 \\
\hline
\end{tabular}

Table 2. Rehabilitation activities- utilisation and costs (euro). Study cohorts: musculoskeletal disorders (MSD, sample size 518) and mental disorders (MD, sample size 294). Means, standard deviations (SD) and medians over those who received one or several interventions.

The total costs of rehabilitation activities amounted for MSD to $40 \%$ of all healthcare interventions, for MD to $38 \%$ of all healthcare interventions.

Nearly half of the cohort received no rehabilitation interventions at all.

\section{Societal costs}

The societal costs of sickness absence, shown in table 3, include resources used for healthcare interventions and economic cost for production loss. 


\begin{tabular}{|c|c|c|c|c|c|c|c|c|}
\hline \multirow[b]{2}{*}{ Sorces of costs } & \multicolumn{4}{|c|}{$\begin{array}{c}\text { Costs (MSD) } \\
\text { (euro) }\end{array}$} & \multicolumn{4}{|c|}{$\begin{array}{c}\text { Costs (MD) } \\
\text { (euro) }\end{array}$} \\
\hline & $\mathrm{N}$ & $\begin{array}{l}\text { Total } \\
\text { costs }\end{array}$ & Mean costs & $\begin{array}{l}\text { Percentage of } \\
\text { production loss }\end{array}$ & $\mathrm{N}$ & $\begin{array}{l}\text { Total } \\
\text { costs }\end{array}$ & Mean costs & $\begin{array}{l}\text { Percentage of } \\
\text { production loss }\end{array}$ \\
\hline $\begin{array}{l}\text { Healthcare } \\
\text { interventions }\end{array}$ & 518 & 288202 & $556 \mathrm{SD} 635$ & 9.3 & 284 & 154674 & $526 \mathrm{SD} 5 e 9$ & 8.2 \\
\hline $\begin{array}{l}\text { Rehabilitation } \\
\text { activities }\end{array}$ & 518 & 113041 & 220 SD 408 & 3.7 & 292 & 58350 & $198 \mathrm{SD} 371$ & 3.1 \\
\hline Production loss & 446 & 2866328 & 5978 SD 5772 & & 287 & 1703623 & $6381 \mathrm{SD} 6526$ & \\
\hline
\end{tabular}

Table 3. Societal costs (euro) of healthcare interventions and production loss. Means over total cohorts, musculoskeletal disorders (MSD, sample size 518) and mental disorders (MD, sample size 294). Reduced sample size of production loss estimates, due to lack of information on gross income.

For MSD, the total mean cost per individual amounts to EUR 5978. Healthcare interventions account for $9.3 \%$ of the production loss and the rehabilitation activities for $3.7 \%$. For MD, the total mean cost per individual amounts to EUR 6381. Healthcare interventions account for $8.2 \%$ and the rehabilitation activities for $3.1 \%$. Thus, about $90 \%$ of the societal costs are due to production losses, and rehabilitation activities consume about $3 \%$. There were no significant differences between MSD and MD groups in means of production loss $(p=0.36)$. The small reduction in sample size due to lack of information on gross income does not change this. 


\section{Discussion}

It is an important societal issue to identify how welfare resources are allocated to promote return-towork for sick-listed people as a means for development of rehabilitation interventions. Work has a positive impact on health [19] and a political strategy in Sweden is to reduce welfare costs through implementation of guidelines for physicians and regulations for the Social Insurance System aiming to cut the length of periods of sick leave. Interventions to promote return-to-work are seldom prioritised in primary healthcare, as the focus lies on treatment and symptom reduction, and there is a lack of knowledge concerning workplace conditions [20]. It has been suggested that the first month after the onset of work-related low-back pain is crucial for halting long-term disability and reliance on welfare benefits [21]. This is most likely also applicable for other disorders. It is therefore important to analyse what resources are allocated to rehabilitation in primary healthcare in order to reduce societal costs due to sick leave.

Studies in the area of MSD and MD, and associated return-to-work interventions have previously focused on effectiveness and cost-effectiveness of treatment and interventions. In general, studies on cost-effectiveness of return-to-work interventions have been questioned with respect to methodological quality $[22,23]$.

In this study, total costs attributable to healthcare and associated with the rehabilitation process were on average quite similar for workers with MSD and MD respectively. This holds for healthcare interventions as a whole as well as for rehabilitative interventions. Some expected differences between MSD and MD were found. Significantly more physiotherapy resources were consumed by individuals with MSD, and significantly more behavioural therapy resources were consumed by those with MD. The average burden to society of all rehabilitative measures was similar for MSD and MD respectively. 
Overall, the largest costs to society were those for loss of production. Healthcare costs accounted for $9.3 \%$ (MSD) and $8.2 \%$ (MD) of the cost for production loss. Comparing the size of costs for loss of production with the amount of resources invested for rehabilitative purposes, it is evident that hypothetically there is great room for improvement. Many researchers advocate multi-professional rehabilitation in order to promote return-to-work. In this study less than $10 \%$ of the patients received this type of rehabilitation, while some patients had a very large number of visits to physiotherapists or behavioural therapists, indicating a more unimodal approach in rehabilitation. Investments in early assessments and tailored rehabilitative measures could pay off very well in terms of earlier return-to-work and thereby less production loss [24].

It should be noted that we used the human capital approach in order to estimate production loss. An alternative approach to evaluating lost production due to sick leave, and one that is rather frequently applied in studies on rehabilitation and return-to-work, is the friction cost method $[25,26]$.

Compared with the human capital approach, the friction cost method is more similar to the way in which employers experience their employees' sick leave. A central assumption in the friction cost method is that sick leave is associated with a cost only during a friction period, until individuals on long-term sick leave have been replaced by someone else. The friction period is often assumed to last for a few months, but in order to make the approach meaningful one would need to set different friction periods for different segments of the labour market. It is reasonable to assume that it takes longer to replace qualified than unqualified workers. With the friction cost method an assumption is often made that the workforce does not perform with $100 \%$ efficiency, implying that there is a slack in the system.

As previously pointed out, the friction cost method may be apprehended as more like real life than the human capital approach, at least from the point of view of employers. However, in most important respects, the theoretical foundation of the friction cost method is missing. One major 
problem is that after some time of sick leave (equal to the friction period) individuals are disconnected from society in the sense that their time is no longer attributed any value $[27,28]$.

With the timeframe used in this study (six months) there would be no major difference in production loss between the human capital approach and the friction cost method. The longer the timeframe analysed, the larger the difference between the two methods.

This study has some limitations, for instance that we have not been able to include rehabilitation measures provided by private caregivers and by occupational health. Even though public healthcare provides the majority of rehabilitation measures, this means that rehabilitation costs as presented in this study are somewhat underestimated, by approximately 5-10\% [29].

From a societal perspective, the costs associated with individuals being sick-listed due to MSD or MD are heavily dominated by loss of production. Resources invested with the purpose of rehabilitating sick-listed individuals are rather limited. So, potentially there may be much to gain by improving the rehabilitation process, and investing more resources for this purpose.

It can be concluded that primary healthcare invests limited resources in the rehabilitation of newly sick-listed people with mental or musculoskeletal diagnoses during the first six months. Costs associated with MSD and MD respectively are on the whole rather similar, with anticipated differences concerning the nature of measures received. The costs to society are mainly due to production losses. 


\section{Acknowledgements}

We would like to thank the County Council of Östergötland (East Sweden) for supplying cost data for the study, and Henrik Magnusson, statistician at Division of Health Care Analysis, Department of Medical and Health Sciences, Linköping University, for carrying out the data analyses. The study was supported by the Swedish Council for Working Life and Social Research, FAS.

\section{Declaration of interests}

There are no conflicts of interest. The study was financed by the Swedish Research Council for Health, Working Life and Welfare (FORTE), and the County Council of Östergötland, Sweden. 


\section{References}

1. Steenstra IA, Anema JR, van Tulder MW, Bongers PM, de Vet HC, van Mechelen W. Economic evaluation of a multi-stage return to work program for workers on sick-leave due to low back pain. J Occup Rehabil 2006;16:557-78.

2. van Oostrom SH, Heymans MW, de Vet HC, van Tulder MW, van Mechelen W, Anema JR. Economic evaluation of a workplace intervention for sick-listed employees with distress. Occup Environ Med 2010;67:603-10.

3. Jensen C, Nielsen CV, Jensen OK, Petersen KD. Cost-effectiveness and cost-benefit of a multidisciplinary intervention compared to a brief intervention to facilitate return to work in sick-listed low-back pain patients. Spine 2013;38:1057-67.

4. Vermeulen SJ, Heymans MW, Anema JR, Schellart AJ, van Mechelen W, van der Beek AJ. Economic evaluation of a participatory return-to-work intervention for temporary agency and unemployed workers sick-listed due to musculoskeletal disorders. Scand J Work Environ Health 2013;39:46-56.

5. Franche RL, Cullen K, Clarke J, Irvin E, Sinclair S, Frank J; Institute for Work \& Health (IWH). Workplace-based return-to-work interventions: a systematic review of the quantitative literature. Workplace-Based RTW Intervention Literature Review Research Team. J Occup Rehabil 2005;15:607-31.

6. Carroll C, Rick J, Pilgrim H, Cameron J, Hillage J. Workplace involvement improves return to work rates among employees with back pain on long-term sick leave: a systematic review of the effectiveness and cost-effectiveness of interventions. Disabil Rehabil 2010;32(8):607-21.

7. Hamberg-van Reenen $\mathrm{HH}$, Proper KI, van den Berg M. Worksite mental health interventions: a systematic review of economic evaluations. Occup Environ Med 2012;69(11):837-45. 
8. Palmer KT, Harris EC, Linaker C, Barker M, Lawrence W, Cooper C, Coggon D. Effectiveness of community- and workplace-based interventions to manage musculoskeletal-related sickness absence and job loss: a systematic review. Rheumatology 2012;51:230-42.

9. van Tulder MW, Koes BW, Bouter LM. A cost-of-illness study of back pain in The Netherlands. Pain 1995;62:233-40.

10. Yelin E, Callahan LF. The economic cost and social and psychological impact of musculoskeletal conditions. National Arthritis Data Work Groups. Arthritis Rheum 1995;38(10):1351-62.

11. Lambeek LC, van Tulder MW, Swinkels IC, Koppes LL, Anema JR, van Mechelen W. The trend in total cost of back pain in The Netherlands in the period 2002 to 2007. Spine 2011;36:1050-8.

12. Waddell G, Burton K. Is work good for your health and well-being? London, HMSO; 2006.

13. K. Ekberg, C. Wåhlin, J. Persson, L. Bernfort, B. Öberg. Is Mobility in the Labor Market a Solution to Sustainable Return to Work for Some Sick Listed Persons? J Occup Rehabil 2011;21:355-365.

14. Rabin R, de Charro F. EQ-5D: a measure of health status from the EuroQol Group. Ann Med 2001;33:337-43.

15 Ilmarinen I. The Work Ability Index. Occupational Medicine 2007;57:160.

16. Gold MR, Siegel JE, Russell LB, Weinstein MC (editors). Cost-effectiveness in health and medicine. Oxford University Press. Oxford, New York, 1996.

17. Wåhlin C, Ekberg K, Persson J, Bernfort L, Öberg B. Evaluation of self-reported work ability and usefulness of interventions among sick-listed patients. J Occup Rehab 2013;23:32-43.

18. Weisbrod B. The valuation of human capital. Journal of Political Economy 1961;69:425-36. 
19. Black C, Frost D. Health at work - an independent review of sickness absence. London: UK Government, Department of Work and pensions; London; 2011.

20. Nilsing E, Söderberg E, Berterö C, Öberg B. Primary health care professionals' experiences of the sick leave process. A focus group study in Sweden. J Occup Rehab 2013; 23:450-61.

21. Krause N, Dasinger LK, Neuhauser F. Modified work and return to work: A review of the literature. J Occup Rehab 1998;8:113-140.

22. Uegaki K, de Bruijne MC, Lambeek L, Anema JR, van der Beek AJ, van Mechelen W, van Tulder M. Economic evaluations of occupational health interventions from a corporate perspective a systematic review of methodological quality. Scand J Work Environ Health 2010;36:273-88.

23. Tompa E, Verbeek J, van Tulder M, de Boer A. Developing guidelines for good practice in the economic evaluation of occupational safety and health interventions. Scand J Work Environ Health 2010;36:313-8.

24. Bültmann U, Sheson D, Olsen J, Hansen C, Lund T, Kilsgaard J. Coordinated and tailored work rehabilitation: A randomized controlled trial with economic evaluation undertaken with workers on sick leave due to musculoskeletal disorders. J Occup Rehabil 2009;19:81-93.

25. Koopmanschap MA, van Ineveld BM. Towards a new approach for estimating indirect costs of disease. Social Science and Medicine 1992;34:1005-10.

26. Koopmanschap MA, Rutten FFH, van Ineveld BM, van Roijen L. The friction cost method for measuring indirect costs of disease. Journal of Health Economics 1995;14:171-89.

27. Johannesson M, Karlsson G. The friction cost method: A comment. Journal of Health Economics 1997;16:249-55.

28. Liljas B. How to calculate indirect costs in economic evaluations. Pharmacoeconomics 1998;13:1-7. 
29. Wåhlin C, Ekberg K, Persson J, Bernfort L, Öberg B. Association between clinical and workrelated interventions and return-to-work for patients with musculoskeletal or mental disorders. J Rehabil Med 2012;44:355-362. 


\section{IMPLICATIONS FOR REHABILITATION}

- Resources invested in rehabilitation for sick-listed with musculoskeletal and mental disorders in Sweden are very small in comparison with the costs of production loss.

- For policy makers, there may be much to gain through investments into improved rehabilitation processes for return to work.

- Heath care professionals need to develop rehabilitative activites aiming for return to work, rather than symptoms treatment only. 